\title{
VIDA ÚTIL DE PILARES DE CONCRETO ARMADO EM FUNÇÃO DA VARIAÇÃO DO COBRIMENTO NOMINAL E DO ADENSAMENTO
}

\author{
VITALINO, EWERTON DE SOUZA \\ Estudante \\ Autarquia do Ensino Superior de Garanhuns - AESGA \\ Pernambuco; Brasil \\ ewertonvitalino25@hotmail.com
}

\author{
OLIVEIRA, MATEUS PEREIRA DE \\ Estudante \\ Autarquia do Ensino Superior de Garanhuns - AESGA \\ Pernambuco; Brasil \\ mateuspereirabr@hotmail.com
}

\author{
OLIVEIRA, ROMILDE ALMEIDA DE \\ Professor \\ Universidade Católica de Pernambuco - UNICAP \\ Pernambuco; Brasil \\ romildealmeida@gmail.com
}

\author{
FERREIRA, LETÍCIA MARIA COSTA \\ Estudante \\ Autarquia do Ensino Superior de Garanhuns \\ Pernambuco; Brasil \\ letimariacostaa@gmail.com
}

\author{
SOARES, RENAN GUSTAVO PACHECO \\ Estudante \\ Universidade Federal de Pernambuco \\ Pernambuco; Brasil \\ renangpsoares@hotmail.com
}

\author{
CARNEIRO, ARNALDO MANOEL PEREIRA \\ Professor \\ Universidade Federal de Pernambuco \\ Pernambuco; Brasil \\ arnaldo2164@ hotmail.com
}

\section{RESUMO}

As edificações ficam expostas a ambientes onde a agressividade ambiental acelera o processo degenerativo dos elementos estruturais em concreto armado e reduz a vida útil do sistema. O cobrimento nominal é um dos fatores que está intimamente ligado à durabilidade e deve ter uma espessura adequada, em função das condições de contorno. Diante disso, o presente estudo teve como objetivo avaliar a vida útil de pilares de concreto armado com seções transversais em concordância e discordância com a NBR 6118 (ABNT, 2014) e NBR 15575 (ABNT, 2013), no que se refere ao cobrimento nominal. Para a realização do trabalho, foram analisados alguns pilares componentes de uma estrutura de muro de uma edificação, além de mais seis amostras de pilares moldadas em laboratório. Três das amostras moldadas não foram vibradas, de modo a simular concretos produzidos de modo empírico, sem controle tecnológico. Os elementos foram submetidos ao ensaio não destrutivo de carbonatação, conforme RILEM (1988). Após o ensaio, constatou-se que o concreto dos pilares do muro estava carbonatado, com perca de seção transvesal das armaduras, após despassivação. Nas amostras moldadas em laboratório, foram medidas as profundidades de carbonatação e constatou-se diferença entre as amostras de diferentes seções transversais, bem como as vibradas e não vibradas de mesma dimensão. Por fim, foi realizado uma estimativa de profundidade de carbonatação através do modelo matemático proposto por Tuutti (1982), onde foi previsto o tempo em que a frente de carbonatação alcançará as armaduras das amostras. Palavras-chave: concreto armado, manifestação patológica, vida útil, carbonatação, qualidade da execução.

\section{ABSTRACT}

Buildings are exposed to environments where environmental aggressiveness accelerates the degenerative process of reinforced concrete structural elements and shortens the life of the system. Nominal coverage is one of the factors that is closely linked to durability and should be of adequate thickness depending on the boundary conditions. Therefore, the present study aimed to evaluate the useful life of reinforced concrete pillars with cross sections in accordance with and disagreeing with NBR 6118 (ABNT, 2014) and NBR 15575 (ABNT, 2013), regarding nominal coverage. To carry out the work, some component pillars of a building wall structure were analyzed, as well as six more samples of laboratory molded columns. Three of the cast samples were not vibrated to simulate empirically produced concretes without technological control. The elements were submitted to the non-destructive carbonation test, according to RILEM (1988). After the test, it was found that the concrete of the wall pillars was carbonated, with loss of cross section of the reinforcement, after depassivation. In the samples molded in the laboratory, the carbonation depths were measured and a difference was found between the samples of different cross sections, as well as the vibrated and non-vibrated ones of the same dimension. Finally, an estimate of carbonation depth was performed using the mathematical model proposed by Tuutti (1982), where it was predicted the time when the carbonation front will reach the reinforcement of the samples.

Keywords: reinforced concrete, pathological manifestation, service life, carbonation, quality of execution. 


\section{INTRODUÇÃO}

O concreto armado é um dos materiais da construção civil mais utilizados no mundo, devido ao seu grande conjunto de qualidade e vantagens. De acordo com o Sindicato Nacional da Indústria do Cimento (2019), foi consumido em 2016 no Brasil cerca de 57 milhões de toneladas de cimento.

Em contrapartida, observa-se diversas edificações de concreto armado sendo executadas diariamente sem o acompanhamento de um profissional habilitado, que resulta em degradações prematuras. Consequentemente, a redução do desempenho e da vida util das estruturas é inevitável.

A vida útil pode ser entendida como o período de tempo entre o início do uso de uma edificação e o momento em que o seu desempenho deixa de atender as exigências usuais, influenciado pela manutenção, reparo e ambiente de exposição (POSSAN; DEMOLINER 2013). Deste modo, a NBR 15575 (ABNT, 2013) garante que a vida útil de uma edificação pode ser prolongada através de ações de manutenções, de forma que o desempenho e vida útil são prolongados.

Helene (2004) observa que o número de estruturas de concreto armado com manifestações patológicas é crescente. Assim, problemas de corrosão das armadurras são os mais encontrados, resultado da desproteção do cobrimento nominal, que promove a despassivação da armadura por carbonatação do concreto.

Segundo Kulakowski (2002), a carbonatação é um fenômeno físico-químico que ocorre pela reação entre produtos alcalinos do concreto, resultado da reação da hidratação do cimento com o gases ácidos presentes no ambiente. Os principais gases ácidos que dão origem a carbonatação e encontrados na atmosfera são: o gás sulfídrico $\left(\mathrm{H}_{2} \mathrm{~S}\right)$, o dióxido de enxofre $\left(\mathrm{SO}_{2}\right)$ e o gás carbônico $\left(\mathrm{CO}_{2}\right)$. Para Possan (2010), o processo de carbonatação interfere na vida útil das estruturas de concreto armado. Assim, o fenômeno reduz a alcalinidade do concreto, alterando as condições da película passivante da armadura e iniciando o processo corrosivo. Assim, o avanço da frente de carbonatação está atrelado à facilidade que o dióxido de carbono encontra para difundir-se através do cobrimento do concreto ao longo do tempo.

Quando há reação de carbonatação, os compostos da pasta hidratada como o hidróxido de potássio (KOH), hidróxido de sódio $(\mathrm{NaOH})$ e o hidróxido de cálcio $\left(\mathrm{Ca}(\mathrm{OH})_{2}\right)$, são consumidos. Desta forma, o pH de precipitação do concreto que originalmente seria acima de 12 é reduzido para abaixo de 9, valor insuficiente para proteger a armadura (KULAKOWSKI, 2002).

Ferreira (2013), garante que além da diminuição do pH, o processo de carbonatação no concreto pode gerar outros problemas, como microfissuras. Sendo assim, é de suma importância garantir o cobrimento e a qualidade do concreto, já que é nesta região em que inicia todo o processo de carbonatação. Desse modo, diversos fatores podem influenciar e afetar a velocidade da carbonatação do concreto. Assim, estes fatores estão ligados ao sistema de poros e pH do concreto, de forma que são alterados a partir da composição e execução das estruturas de concreto.

Possan (2010) indica que os principais fatores que afetam o fenômeno da carbonatação, são: condições ambientais (concentração de $\mathrm{CO}_{2}$, umidade relativa do ar e temperatura); condições de exposições (ambientes interno, externo, protegido ou desprotegido da chuva); e característica do concreto (composição química do cimento, traço e execução).

Diante do exposto e com foco no alerta à sociedade para evitar a prática da autoconstrução, onde não são seguidos muitos dos requisitos mínimos normativos, direcionados à durabilidade do sistema, o presente trabalho teve como objetivo avaliar as variações da vida útil dos pilares de concreto armado em função da espessura do cobrimento nominal, das seções transversais, assim como também o fato de haver ou não o adensamento do concreto. Para tanto, foram analisados seis diferentes amostras de pilares moldados em laboratório, bem como quatro pilares componentes da estrutura de um muro, onde foi realizado ensaio de carbonatação, medidas suas profundidades carbontadas, e por fim, feito uma estimativa de profundidade de carbontação.

\section{METODOLOGIA}

Com o intuito de avaliar a carbonatação em difetentes seções transversais, foi feita a moldagem de seis amostras de pilares de concreto armado. Estas amostras simulam pilares em conformidade e desconformidade com a NBR 6118 (ABNT, 2014), NBR 15575 (ABNT, 2013) e NBR 14931 (ABNT, 2004). Desta forma, três destas amostras não foram vibradas, buscando simular peças de concretro sem o controle de execução necessário, como comumente se observa nas 
construções. Em adição, foi analisada uma estrutura já existente de um muro com pilares de concreto armado, onde em campo foi feito o levantamento da estrutura, obtendo-se os dados referente as suas dimensões e cobrimentos. Tanto as amostras moldadas, como os pilares componente do muro, foram submetidos ao ensaio de carbonatação, medidas suas profundidades carbonatadas e feito uma estimativa de carbonatação até que o fenômeno atinja as armaduras.

Para a realização da estimativa de tempo até a carbonatação atingir as armaduras, adotou-se o modelo matemático proposto por Tuutti (1982), por ser um dos mais utilizados. Assim, o modelo é proporional à raiz quadrada do tempo de exposição ao $\mathrm{CO}_{2}$, resultando na seguinte equação:

$\mathrm{Ec}=\mathrm{k} \cdot V_{\mathrm{t}}$

Onde: $\mathrm{Ec}=$ profundidade carbonatada $(\mathrm{mm}) ; \mathrm{t}=$ tempo de exposição $($ anos $) ; \mathrm{k}=$ constante.

\subsection{Materiais}

\subsubsection{Cimento}

O cimento utilizado foi o CP II-F-32, padronizado pela NBR 16697 (ABNT, 2018) e obtido no comércio local. Escolhido pelo fato de ser um dos mais utilizados. Segundo a Associação Brasileira de Cimento Portland (2018), tal cimento utilizado possui aplicações gerais, sendo indicado desde a utilização para argamassas até estruturas de concreto armado e protendido. Apresenta, ainda, em sua composição a adição de material carbonático (fíller), de 6 a $10 \%$.

\subsubsection{Agregados miúdos e graúdos}

Agregados miúdos são os grãos que passam pela peneira com abertura de malha de 4,75 mm, ficando retidos na peneira de malha 0,15 mm NBR 7211 (ABNT, 2009). Para a execução do concreto usado na elaboração das amostras foi utilizada areia lavada proveniente da cidade de Angelim-PE.

De acordo com a NBR 7211 (ABNT, 2009) em seu item 3.1, o agregado graúdo é definido como os grãos que passam pela peneira com abertura de malha $75 \mathrm{~mm}$ e ficam retidos na peneira com abertura de malha de $4,75 \mathrm{~mm}$. Na confecção do concreto foi utilizado material britado que passou pela peneira de malha $19 \mathrm{~mm}$.

\subsubsection{Armadura}

As armaduras utilizadas em todas as amostras dos pilares foram vergalhões CA-50 $10 \mathrm{~mm}$ (3/8"), em seu sentido longitudinal. No sentido transversal vergalhão CA-60 de $5 \mathrm{~mm}$ e 4,2 mm.

\subsection{Produção das amostras moldadas}

\subsubsection{Dosagem}

Visando se aproximar da realidade das obras, pelo fato de que grande parte das construções não adotam um método de dosagem bem definido, na dosagem do concreto foi utilizado um traço 1:2:3 (cimento: areia: brita), a/c 0,50, medido em volume, bastante utilizado na região. Todo o concreto utilizado foi misturado em betoneira com capacidade de 400 litros. Os materiais foram dispostos na betoneira seguindo a ordem: $100 \%$ da brita e $50 \%$ de água, $100 \%$ do aglomerante, restante da água e por fim toda a areia. Desta forma, as amostras dos pilares foram moldadas em fôrmas de madeira, e umedecidas antes da concretagem.

\subsubsection{Caracterização das amostras}

Os pilares moldados em laboratório foram divididos entre os que foram vibrados e os não vibrados. As amostras vibradas manualmente receberam a sigla VM. As não vibradas, a sigla NV. Assim, os vibrados foram as amostras VM1, VM3 e VM5, com adensamento realizado de forma manual, por meio de barras de aço com a função de compactar melhor o sistema e reduzir a quantidade de ar incorporado na mistura. Os pilares não vibrados (amostras NV2, NV4 e NV6) foram aqueles em que apenas foi lançado o concreto na forma e uniformizada sua superfície com auxílio de colher de pedreiro. Na Tabela 1, um resumo das características do processo de moldagem dos pilares estão demonstrados. 
Para armadura longitudinal de todas as amostras, usou-se 4 barras de aço CA-50 com diâmetros de $10 \mathrm{~mm}$.

Para os estribos das amostras VM1, NV2, VM,3 e NV4 foi utilizado vergalhão CA-60 de 5 mm, dobrado in loco. Nas amostras VM5 e NV6 foram utilizados estribos comercializados, feito com vergalhão CA-60 de 4,2 mm, obtido no comércio local, frequentemente usado nas obras, mesmo não estando em concordâcia com a norma do concreto. A escolha desses estribos se deu por ocasião de ainda estarem sendo comercializados materiais em descordância dos preceitos normativos, onde induz a população ao uso, por serem materiais disponíveis.

Para as amostras, adotou-se uma altura de $50 \mathrm{~cm}$ e foram colocados três estribos espaçados a cada $15 \mathrm{~cm}$ (Figura 1).

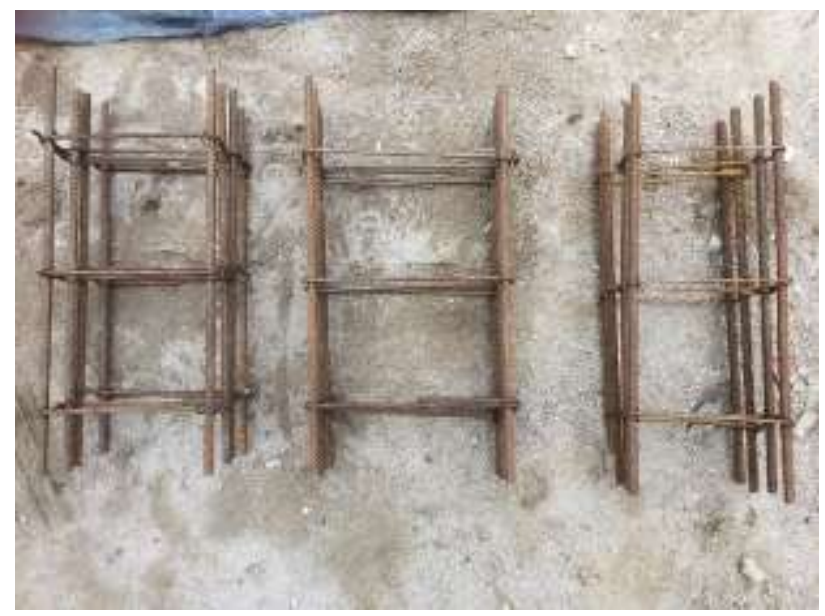

Figura 1: Armação da ferragem.

A altura de $50 \mathrm{~cm}$ foi para que fosse possível romper as amostras na prensa do laboratório. Após a confecção, foi necessário esperar 28 dias relativo ao tempo de cura do concreto, de forma que ficaram alocadas em ambiente seco e externo, como se verifica na Figura 2.

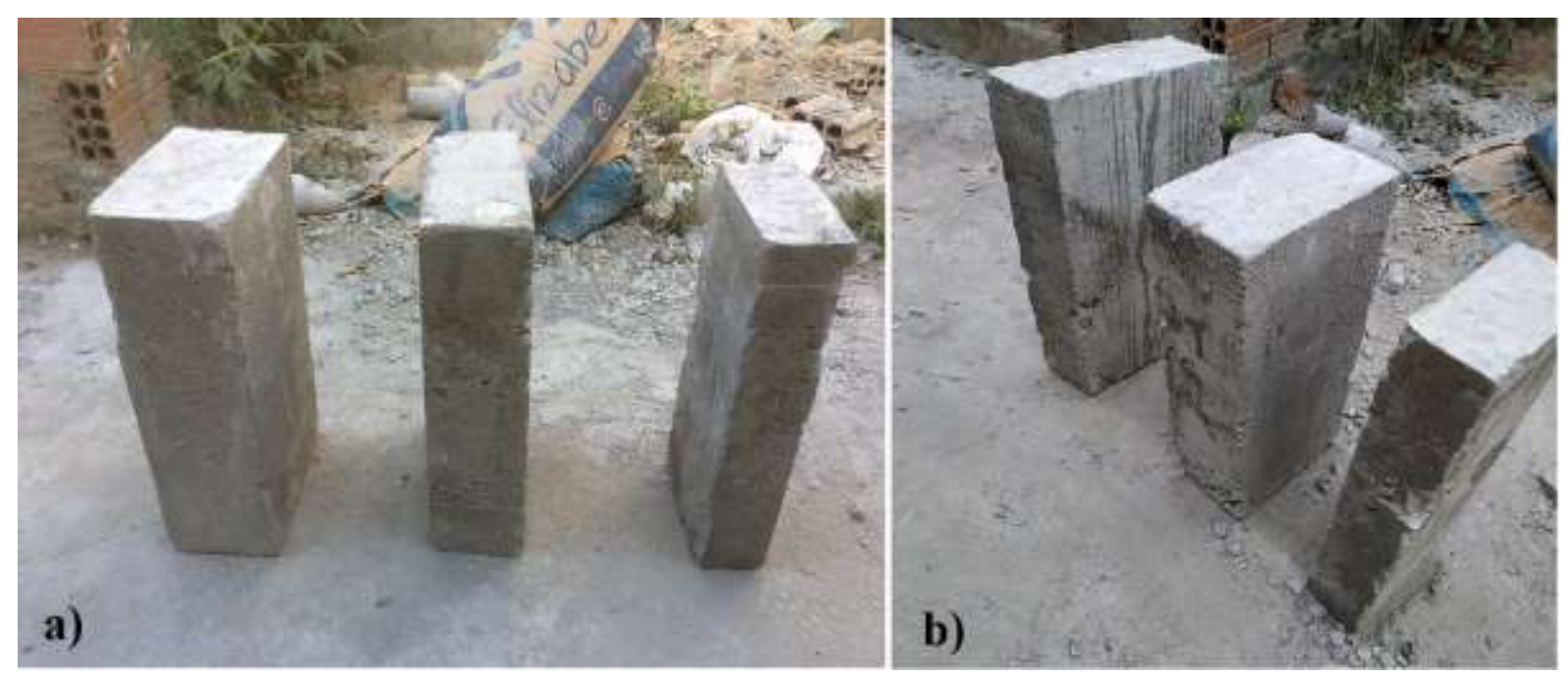

Figura 2: Amostras 1 a 6.

Na Figura 2a, estão dispostas as amostras VM1, VM3 e VM5, respectivamente, referentes aos três primeiros pilares cuja condição de adensamento foi vibrado manualmente. Na Figura 2b, estão apresentadas as amostras NV2, NV4 e NV6, respectivamente, onde foram os pilares que não foram vibrados.

A cura em local aberto foi necessária para se aproximar das condições comuns em que as construções são realizadas. Na Tabela 1, as características consideradas para cada uma das amostras produzidas podem ser identificadas. 
Tabela 1 - Resumo das amostras moldadas

\begin{tabular}{c|c|c|c|c|c|c|c|c}
\hline Amostra & SIGLA & $\begin{array}{c}\text { Dimensão } \\
(\mathrm{cm})\end{array}$ & $\begin{array}{c}\text { Armadura } \\
\text { Longitudinal }\end{array}$ & $\begin{array}{c}\text { Estribo } \\
(\mathrm{cm})\end{array}$ & $\begin{array}{c}\text { Bitola } \\
\text { Estribos }\end{array}$ & $\begin{array}{c}\text { Espaçamento } \\
\text { estribos }(\mathrm{cm})\end{array}$ & $\begin{array}{c}\text { Cobrimento } \\
(\mathrm{mm})\end{array}$ & Adensamento \\
\hline 1 & VM1 & $14 \times 26$ & $4 \phi 10.00 \mathrm{~mm}$ & $8 \times 20$ & $\phi \mathrm{t} 5.0 \mathrm{~mm}$ & 15 & 30 & Vibrado \\
\hline 2 & NV2 & $14 \times 26$ & $4 \phi 10.00 \mathrm{~mm}$ & $8 \times 20$ & $\phi \mathrm{t} 5.0 \mathrm{~mm}$ & 15 & 30 & Não vibrado \\
\hline 3 & VM3 & $12 \times 30$ & $4 \phi 10.00 \mathrm{~mm}$ & $6 \times 24$ & $\phi \mathrm{t} 5.0 \mathrm{~mm}$ & 15 & 30 & Vibrado \\
\hline 4 & NV4 & $12 \times 30$ & $4 \phi 10.00 \mathrm{~mm}$ & $6 \times 24$ & $\phi \mathrm{t} 5.0 \mathrm{~mm}$ & 15 & 30 & Não vibrado \\
\hline 5 & VM5 & $9 \times 20$ & $4 \phi 10.00 \mathrm{~mm}$ & $7 \times 17$ & $\phi \mathrm{t} 4.2 \mathrm{~mm}$ & 15 & 10 & Vibrado \\
\hline 6 & NV6 & $9 \times 20$ & $4 \phi 10.00 \mathrm{~mm}$ & $7 \times 17$ & $\phi \mathrm{t} 4.2 \mathrm{~mm}$ & 15 & 10 & Não vibrado \\
\hline
\end{tabular}

As amostras VM1, VM3 e VM5 foram vibradas manualmente. As NV2, NV4 e NV6 não foram vibradas. Essa vibração manual, ou até mesmo a não vibração, também tem foco na aproximação do método empírico usado no cotidiano. As seções transversais das VM3 e NV4 simulam os requisitos da antiga NBR 6118 (ABNT, 2003), onde alguns construtores ainda fazem uso com a justificativa de não sacar os pilares e ficar em contraponto com a estética. As VM5 e NV6, além das mesmas justificativas das amostras VM3 e NV4, as armaduras com estribo 7x17 ainda tem sido comercializadas, mesmo que em desacordo com as normas. O cobrimento nominal das VM5 e NV6 também foram reduzidos pelo fato de em algumas situações, construtores usam de pilares com a mesma espessura de uma alvenaria de bloco cerâmico de 8 furos, com largura de apenas $9 \mathrm{~cm}$, com foco apenas na estética.

\subsection{Descrição dos pilares do muro}

Paralelo às amostras moldadas, foi analisado também a estrutura de um muro de uma edificação na cidade de Garanhuns-PE, que possui aproximadamente 2 anos de idade. Desta forma, foram escolhidos quatro pilares de forma aleatória do muro para a realização de ensaios de carbonatação, onde em campo foi medido as dimensões destes pilares, bem como as medidas referente aos seus cobrimentos nominais e diâmetros das armaduras utilizadas. As armaduras dos pilares eram compostas de quatro barras de $10 \mathrm{~mm}$ na direção longitudinal, estribos $7 \times 17 \mathrm{~cm}$ de 4,2 mm de diâmetro em suas seções transversais. Na Tabela 2 constam os dados referentes às características físicas dos pilares do muro.

Tabela 2 - Resumo dos pilares do muro

\begin{tabular}{c|c|c|c|c|c|c}
\hline Pilar & SIGLA & Dimensão $(\mathrm{cm})$ & $\begin{array}{c}\text { Armadura } \\
\text { Longitudinal }\end{array}$ & Cobrimento $(\mathrm{mm})$ & $\begin{array}{c}\text { Armadura } \\
\text { Longitudinal }\end{array}$ & $\begin{array}{c}\text { Armadura } \\
\text { Transversal }\end{array}$ \\
\hline 1 & P1 & $10 \times 20$ & $4 \phi 10.00 \mathrm{~mm}$ & 10 & $4 \Phi 10 \mathrm{~mm}$ & $\Phi \mathrm{t} 4.2 \mathrm{~mm} \mathrm{c} / 15 \mathrm{~cm}$ \\
\hline 2 & P2 & $9 \times 20$ & $4 \phi 10.00 \mathrm{~mm}$ & 15 & $4 \Phi 10 \mathrm{~mm}$ & $\Phi \mathrm{t} 4.2 \mathrm{~mm} \mathrm{c} / 15 \mathrm{~cm}$ \\
\hline 3 & P3 & $9,5 \times 20$ & $4 \phi 10.00 \mathrm{~mm}$ & 20 & $4 \Phi 10 \mathrm{~mm}$ & $\Phi \mathrm{t} 4.2 \mathrm{~mm} \mathrm{c} 15 \mathrm{~cm}$ \\
\hline 4 & P4 & $9 \times 20$ & $4 \phi 10.00 \mathrm{~mm}$ & 10 & $4 \Phi 10 \mathrm{~mm}$ & $\Phi \mathrm{t} 4.2 \mathrm{~mm} \mathrm{c} / 15 \mathrm{~cm}$ \\
\hline
\end{tabular}

Em boa parte dos pilares, observou-se falhas de execução, como a falta de adensamento do concreto, resultando em bicheiras, deixando as armaduras expostas. Isso favoreceu o avanço da frente de carbonatação, com a consequente despassivação das armaduras. Nas Figuras 3 e 4 que seguem, os pilares do muro analisados podem ser identificados.

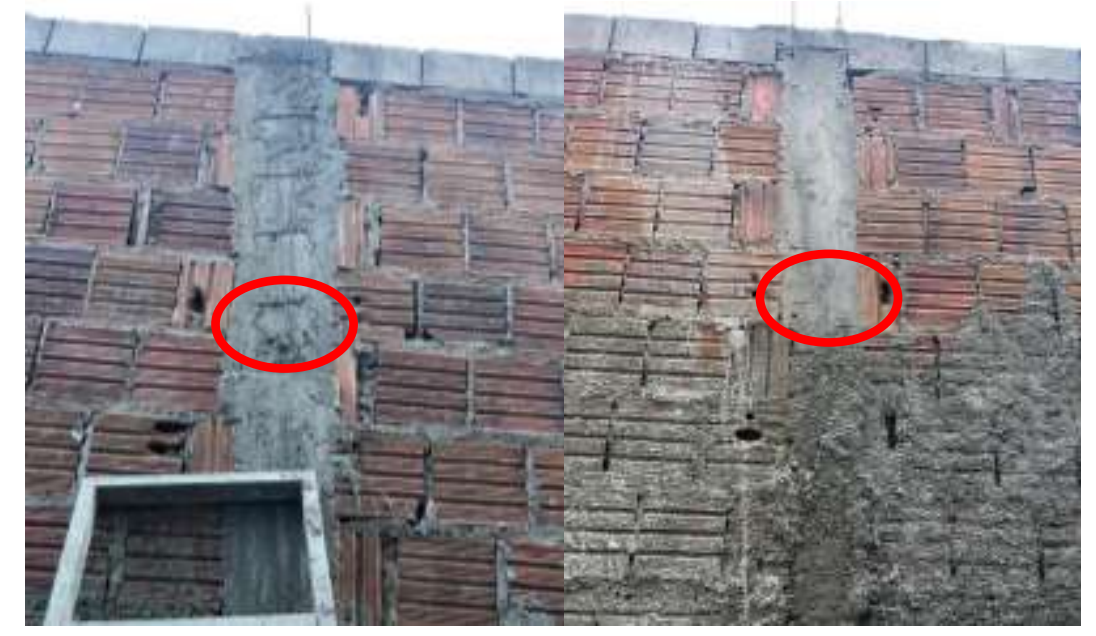

Figura 3: Pilares 1 e 2, respectivamente. 


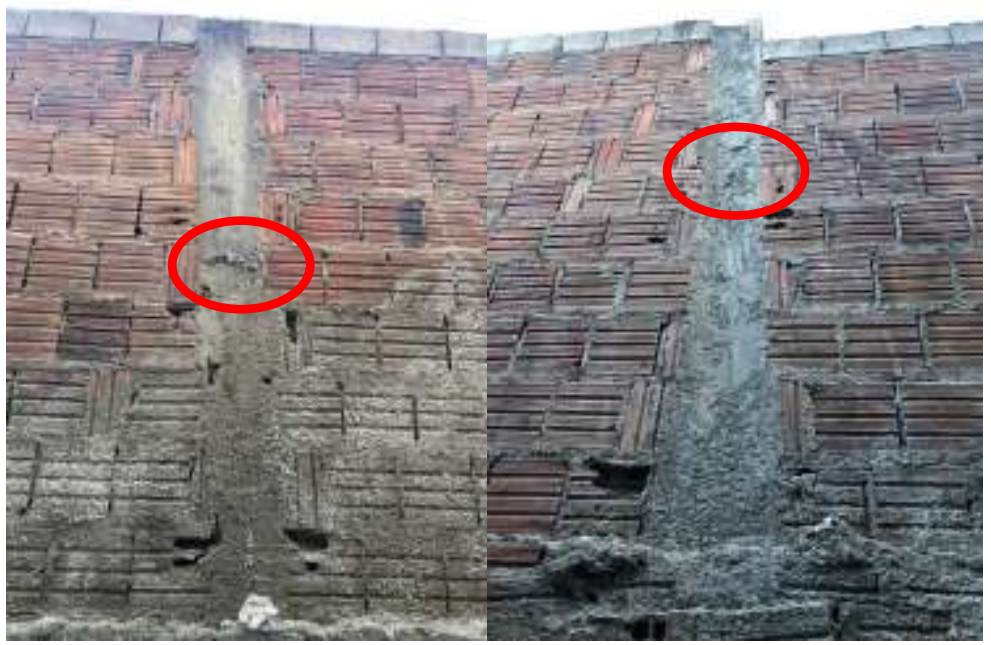

Figura 4: Pilares 3 e 4, respectivamente.

As partes destacadas foram as regiões onde foram realizados os ensaios de carbonatação. Como em alguns desses pontos haviam armaduras expostas, verificou-se que a profundidade de carbonatação era igual ao cobrimento nominal.

\subsection{Ensaio de carbonatação e medição de profundidade carbonatada}

Para a realização do ensaio de carbonatação, adotou-se o método recomendado pela RILEM (1988), que propõe a utilização de uma solução com $1 \%$ de fenolftaleína em $70 \%$ de álcool etílico e $29 \%$ de água destilada. Kulakowski (2002) explica que para efetuar as medidas da frente de carbonatação, o indicador constituído de uma solução é aspergido sobre a superfície fraturada do concreto. Para a fenolftaleína, quando empregado, a superfície se apresentará incolor para a região carbonatada, enquanto que a não carbonatada apresentará o vermelho carmim.

Na realização do ensaio de carbonatação para a avaliação, foi feito o rompimento do concreto em um dos vértices do pilar, na parte superior, ou procurou-se aplicar nas partes que apresentavam falhas de concretagem (comum nos pilares moldados que não foram vibrados e nos pilares do muro), estando já algumas regiões com a armadura exposta, pois sabe-se que nessas regiões a frente de carbonatação avança com maior facilidade. Posteriormente, após a fratura do concreto até as armaduras, para as amostras moldadas, foram medidas as profundidades de carbonatação (Figura 5).

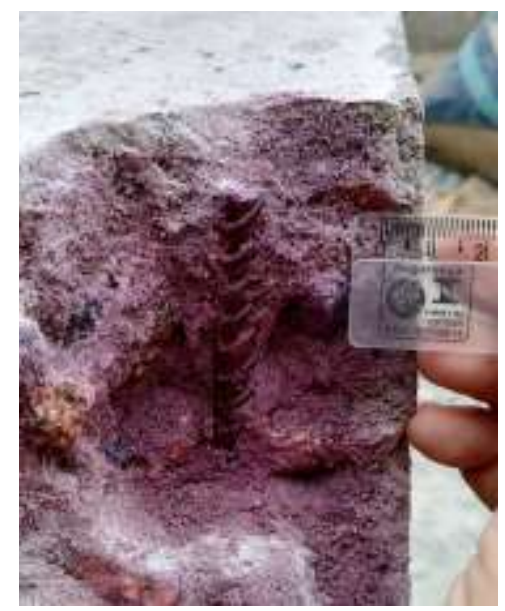

Figura 5: Medição de profundidade de carbonatação das amostras moldadas.

\section{RESULTADOS}

\subsection{Amostras moldadas}

Após a realização do ensaio de carbonatação das amostras moldadas, foram coletadas as medidas de profundidades de carbonatação, como observa-se na Tabela 3. 
Tabela 3 - Medidas de profundidade de carbonatação

\begin{tabular}{c|c|c}
\hline Amostra & Cobrimento $(\mathrm{mm})$ & Ec $(\mathrm{mm})$ \\
\hline VM1 & 30 & 3,0 \\
\hline NV2 & 30 & 9,0 \\
\hline VM3 & 30 & 4,0 \\
\hline NV4 & 30 & 6,0 \\
\hline VM5 & 10 & 6,0 \\
\hline NV6 & 10 & 9,0 \\
\hline
\end{tabular}

No geral, observa-se na Tabela 3 que as amostras NV2, NV4 e NV6 apresentaram maiores profundidades de carbonatação. Isto pode ser justificado pela falta de adensamento que contribuiu pra o avanço da frente de carbonatação, deixando em alguns casos a armadura exposta. Alta porosidade e falhas de concretagem contribuem para o avanço.

Esses valores afirmam o colocado por Kulakowski (2002) e Wang, Su e Du (2018), onde declaram que a velocidade do avanço de carbonatação está ligada a questões de qualidade de execução, idade, rigidez e tensões atuantes no concreto, sendo as questões de adensamento de suma importância para o prolongamento da vida útil. Sendo assim, o mesmo afirma que uma compactação do concreto deficiente pode acarretar em falhas, gerando ninhos de concretagem, excesso de ar aprisionado, alta porosidade e assim facilitando a penetração e propagação da frente de carbonatação.

Para melhor comparar as amostras de mesma dimensão, na Tabela 4 foram calculados em porcentagem, o aumento da profundidade que as amostras não vibradas carbonataram a mais do que as vibradas. Assim, destacando essa variação apenas pelo fato de o concreto não ser adensado corretamente.

\begin{tabular}{|c|c|c|c|}
\hline Amostra & $\mathrm{Ec}(\mathrm{mm})$ & Dimensão $(\mathrm{cm})$ & Aumento da profundidade (\%) \\
\hline VM1 & 3 & \multirow{2}{*}{$14 \times 26$} & \multirow[b]{2}{*}{200} \\
\hline NV2 & 9 & & \\
\hline VM3 & 4 & \multirow{2}{*}{$12 \times 30$} & \multirow{2}{*}{50} \\
\hline NV4 & 6 & & \\
\hline VM5 & 6 & \multirow{2}{*}{$9 \times 20$} & \multirow{2}{*}{50} \\
\hline NV6 & 9 & & \\
\hline
\end{tabular}

É clara a influência do adensamento no combate à carbonatação do sistema. E isso considerando apenas a vibração manual. Se vibrado mecanicamente, os índices ainda poderão ser maiores.

\subsection{Pilares do muro}

Ao serem realizados os ensaios de carbonatação nos pilares do muro, percebeu-se a ação do dióxido de carbono, de forma que todos os pilares da estrutura do muro estavam carbonatados, como se observa nas Figuras 6 e 7.

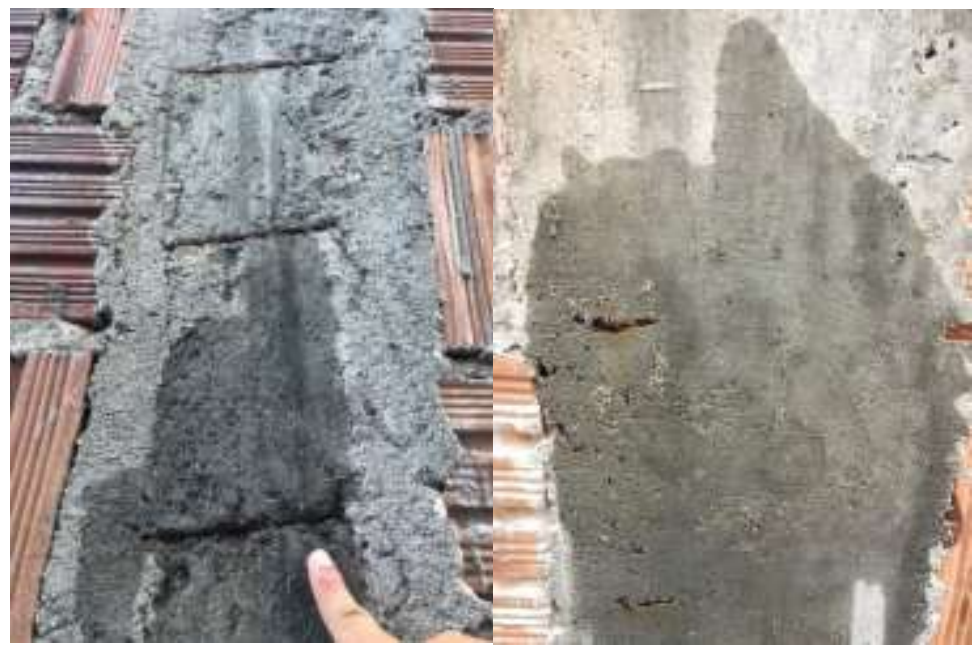

Figura 6: Carbonatação dos pilares 1 e 2. 


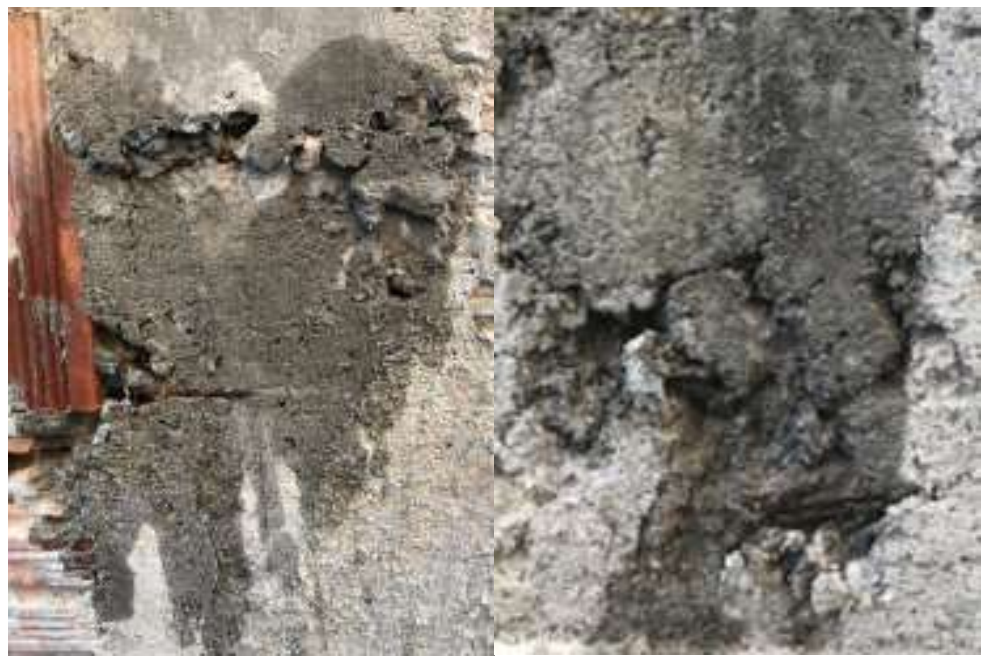

Figura 7: Carbonatação dos pilares 3 e 4.

Sendo assim, após o ensaio, pôde-se confirmar que o pH do concreto foi diminuído, já que toda região em que foi aspergido a solução com fenolftaleína permaneceu incolor. Desta forma, percebeu-se que o avanço da frente de carbonatação até as armaduras foi beneficiado por não seguir os parâmetros normativos de projeto, possuindo um cobrimento nominal inferior ao normativo.

Em relação à presença do dióxido de carbono, os resultados obtidos foram de acordo com a expectativa. Como visto nas imagens acima, a qualidade e execução do concreto, assim como o mal adensamento, foram fatores primordiais para que houvesse maior penetração do fenômeno.

\subsection{Avaliação da estimativa de profundidade de carbonatação}

Com o objetivo de fazer uma estimativa e avaliar a profundidade de carbonatação ao longo do tempo, através da equação de Tuutti (1982) foi feito uma análise para as amostras moldadas e para os pilares da estrutura do muro. Assim, para a estimativa, foi obtido o coeficiente de difusão $\mathrm{k}$, dado em $\left(\mathrm{mm} / \mathrm{ano}^{0,5}\right)$. Deste modo, o coeficiente foi obtido de acordo com a profundidade de carbonatação encontrado em cada amostra e pilar.

\subsubsection{Amostras moldadas}

Para as amostras moldadas, após serem obtidas as profundidades carbonatadas (Ec) e calculados os coeficientes de difusão (k), foi calculado o tempo (anos) necessário para que a carbonatação atinja as armaduras, ou seja percorra todo o cobrimento dado em cada amostra, como observa-se na Tabela 5.

Tabela 5 - Estimativa de tempo para carbonatação atingir as armaduras

\begin{tabular}{c|c|c|c|c}
\hline Amostra & Cobrimento $(\mathrm{mm})$ & $\mathrm{Ec}(\mathrm{mm})$ & $\mathrm{K}\left(\mathrm{mm} / \mathrm{ano}^{0,5}\right)$ & $\begin{array}{c}\text { Estimativa para carbonatação } \\
\text { atingir as armaduras (anos) }\end{array}$ \\
\hline VM1 & 30 & 3,0 & 10,61 & 7,99 \\
\hline NV2 & 30 & 9,0 & 31,82 & 0,89 \\
\hline VM3 & 30 & 4,0 & 14,14 & 4,50 \\
\hline NV4 & 30 & 6,0 & 21,21 & 2,00 \\
\hline VM5 & 10 & 6,0 & 21,21 & 0,22 \\
\hline NV6 & 10 & 9,0 & 31,82 & 0,10 \\
\hline
\end{tabular}

Ao analisar a Tabela 5, constata-se que só o fato do não adensamento do concreto, reduções significativas de tempo para a despassivação das armaduras são identificadas.

Na Figura 8, através dos graficos é possível observar todo o avanço da frente de carbonatação individualmente das amostras ao longo dos anos. 

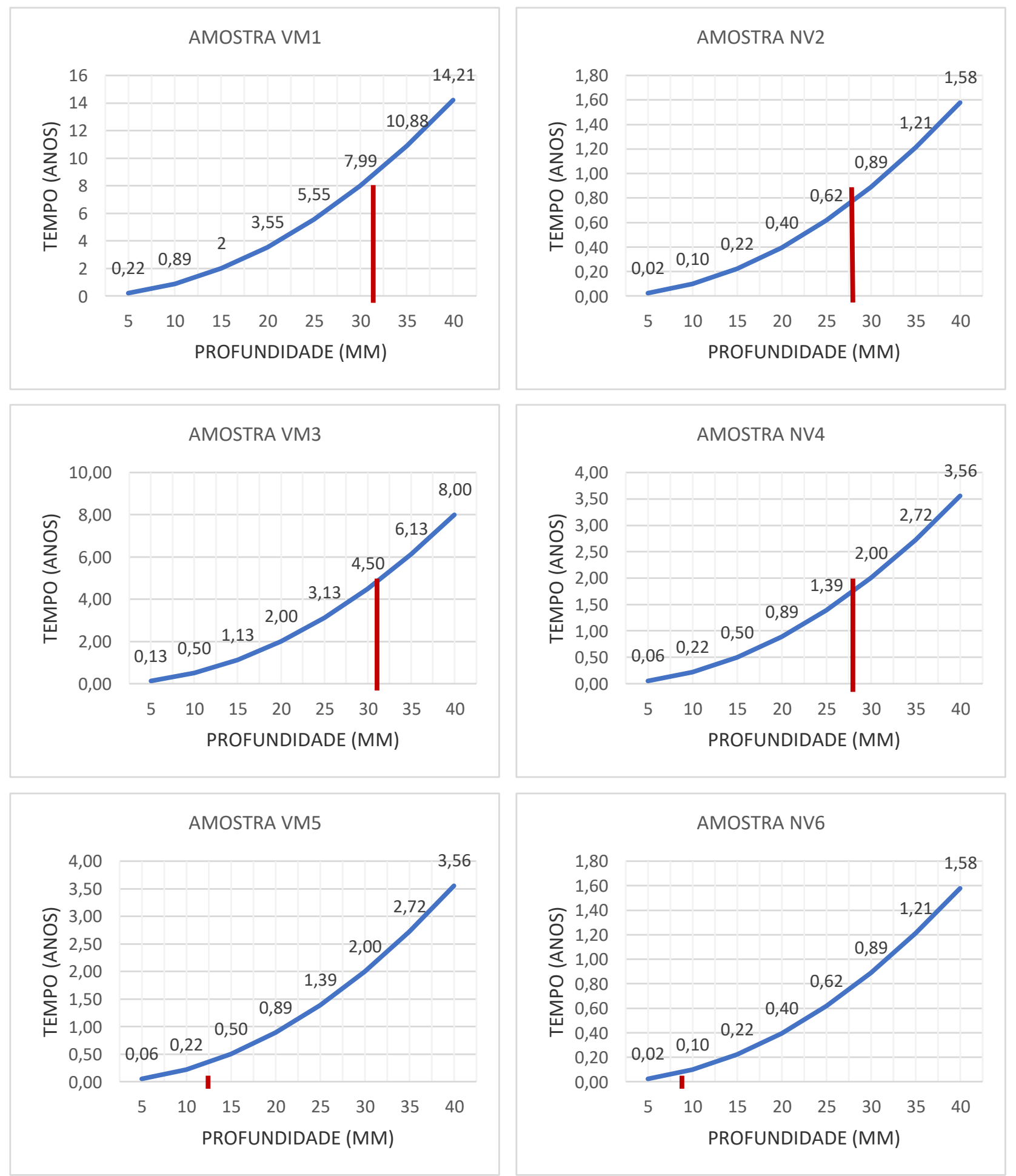

Figura 8: Estimativa de profundidade de carbonatação até as armaduras.

Conforme os resultados obtidos, a amostra VM1 possui o melhor desempenho, com relação às demais, já que a mesma foi moldada seguindo os critérios de dimensionamentos estabelecidos na NBR 6118 (ABNT, 2014) e a NBR 14931 (ABNT, 2004). Por outro lado, a amostra NV2 também seguiu os critérios da NBR 6118 (ABNT, 2014), porém o concreto não foi vibrado na execução, como recomenda a norma, de forma que resultou em falhas de adensamento causando bicheiras, que diminuiu a sua vida útil.

As amostras VM3 e NV4, confeccionadas a partir da NBR 15575 (ABNT, 2013) tiveram resultados semelhantes, porém, abaixo da amostra VM1, tendo uma estimativa inferior também à amostra NV4 não vibrada, como era esperado. 
Com um cobrimento inferior às demais amostras, a VM5 e a NV6 possui uma estimativa de tempo até a carbonatação chegar as armaduras bastante inferior às outras. Assim, percebe-se que a profundidade de carbonatação está muito próximo de atingir as armaduras. Desta forma, constata-se a ineficácia do uso de pilares com este tipo de estrutura.

Isto comprova a consideração que deve ser dado a NBR 6118 (ABNT, 2014) quanto ao cobrimento nominal mínimo das armaduras, sabendo que o mesmo pode influenciar na vida útil das estruturas de concreto armado, já que o mesmo forma uma barreira

Sendo assim, obtidas as estimativas de tempo necessário para que a carbonatação atinja as armaduras, calculou-se o tempo remanescente até que a carbonatação chegue ao nível das armaduras. Para isso, foi descontado a idade da estrutura, dos dados obtidos da estimativa, obtendo-se os resultados apresentados na Tabela 6.

Tabela 6 - Tempo remanescente até que a carbonatação atinja as armaduras

\begin{tabular}{c|c|c|c}
\hline Amostra & $\mathrm{K}\left(\mathrm{mm} / \mathrm{ano}^{0,5}\right)$ & $\begin{array}{c}\text { Estimativa para carbonatação } \\
\text { atingir as armaduras (anos) }\end{array}$ & $\begin{array}{c}\text { Tempo remanescente } \\
\text { (anos) }\end{array}$ \\
\hline VM1 & 10,61 & 7,99 & 7,91 \\
\hline NV2 & 31,82 & 0,89 & 0,81 \\
\hline VM3 & 14,14 & 4,50 & 4,42 \\
\hline NV4 & 21,21 & 2,00 & 1,92 \\
\hline VM5 & 21,21 & 0,22 & 0,14 \\
\hline NV6 & 31,82 & 0,10 & 0,02 \\
\hline
\end{tabular}

Percebe-se que as amostras VM5 e NV6 estão muito próximas de terem suas armaduras atingidas pelo dióxido de carbono, de forma que devem ser tomadas medidas de intervenção.

Diante disso, percebe-se o porquê de boa parte das construções de concreto armado terem sua durabilidade e vida útil reduzida, fruto de uma má execução, em que vários construtores não atentam para tal detalhe.

\subsubsection{Pilares do muro}

Visando fazer um comparativo de vida útil dos pilares do muro com os cobrimentos reais adotados e com o recomendado pela NBR 6118 (ABNT, 2014), buscou-se estimar o tempo que levaria até que a frente de carbonatação alcançasse a armadura caso os pilares tivessem seguido o cobrimento de $3 \mathrm{~cm}$ estabelecido pela norma.

Para os pilares da estrutura do muro, não foi necessário o rompimento e abertura para medição da profundidade carbonatada, pois percebeu-se durante o ensaio que todo o cobrimento estava carbonatado, com casos em que a armaduras estavam expostas.

Assim sendo, considerou-se que a profundidade carbonatada é igual a espessura do cobrimento nominal, já que o dióxido de carbono havia avançado até as armaduras. Para organizar os dados já obtidos, com os valores calculados de $\mathrm{k}$ para cada pilar, tem-se a Tabela 7.

Tabela 7 - Coeficiente de difusão $(\mathrm{k})$ dos pilares do muro

\begin{tabular}{c|c|c}
\hline Pilar & Cobrimento $(\mathrm{mm})$ & $\mathrm{K}\left(\mathrm{mm} / \mathrm{ano}^{0,5}\right)$ \\
\hline P1 & 10 & 7,07 \\
\hline P2 & 15 & 10,61 \\
\hline P3 & 20 & 14,14 \\
\hline P4 & 10 & 7,07 \\
\hline
\end{tabular}

Como se pode ver acima, o coeficiente k aumenta em decorrência do aumento do cobrimento nominal. Este fato se dá pelo motivo de que foi medida a profundidade de carbonatação até as armaduras, de forma que todas as espessuras de cobrimento estavam carbonatadas.

Assim sendo, ao fazer aplicação da equação de Tuutti (1982) para obter o coeficiente k, considerou-se que a frente de carbonatação no pilar que possui $1 \mathrm{~cm}$ de cobrimento, assim como no que possui $2 \mathrm{~cm}$, alcançou as armaduras no mesmo período de tempo ( 2 anos), o que na realidade não acontece, já que os pilares estão expostos ao mesmo ambiente 
e possui características construtivas semelhantes. Fazendo esta consideração, os pilares com menores cobrimentos teriam a espessura menor para medir a profundidade de carbonatação.

Assim, para se ter um resultado condizente com a realidade, escolheu-se o pilar P3 para a estimativa com o $\mathrm{k}=14,14$, visto que o mesmo possui o cobrimento maior e ao longo dos dois anos todo o cobrimento foi carbonatado.

Desta forma, sabe-se que o fenômeno da carbonatação atingiu as armaduras em dois anos, uma vez que o cobrimento é de $2 \mathrm{~cm}$. A recomendação da NBR 6118 (ABNT, 2014) para este pilar, é que o mesmo possuísse $3 \mathrm{~cm}$ de cobrimento. Na Figura 9, observa-se o tempo estimado para a carbonatação atingir as armaduras, caso a estrutura tivesse o cobrimento de $3 \mathrm{~cm}$.

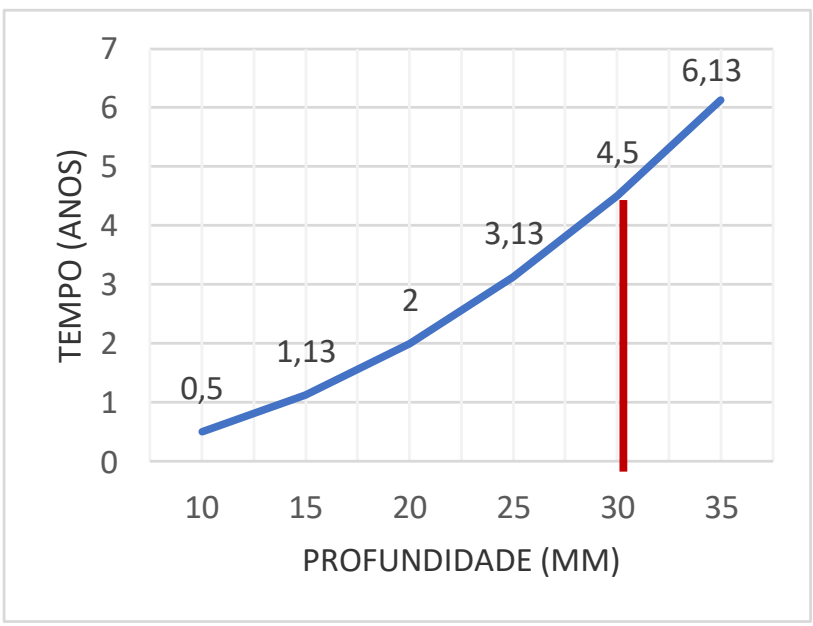

Figura 9: Estimativa de profundidade para cobrimento de $3 \mathrm{~cm}$.

Como visto na Figura 10, caso o pilar P3 tivesse seguido a exigência de cobrimento mínimo de $3 \mathrm{~cm}$, o tempo para que a carbonatação atingisse a armadura seria de 4,5 anos, um aumento de $125 \%$ em relação ao modelo real com $2 \mathrm{~cm}$ e carbonatado em dois anos. Isso com o concreto nas mesmas condições. Para aumento desse tempo de vida útil, o fator compacidade do concreto deveria ser maior.

Os resultados acima corroboram com Wang, Su e Du (2018) e Andrade (2020), ao destacarem a influência do ambiente por ocasião do índice de $\mathrm{CO}_{2}$ (dióxidode carbono). Também pelas condições executivas, que vão desde a definição do traço do concreto até sua cura, como fatores básicos para redução da porosidade e aumento do fator compacidade do concreto. Aliado a isso, ressalta-se a premissa básica do atendimento aos preceitos normativos vigentes.

\section{CONCLUSÃO}

Percebeu-se que os pilares de dimensão 9x20, e cobrimento nominal de $1 \mathrm{~cm}$, tiveram sua vida útil extremamente reduzida quando comparadas com as demais, já que o fenômeno da carbonatação necessita de uma menor profundidade para chegar as armaduras. Desta forma, ao comparar as amostras VM1 e VM5, de dimensões 14x26 e 9x20 cm respectivamente, percebe-se que houve uma redução de 97,25\% da vida útil da amostra VM5 em relação a VM1.

O aumento significativo das profundidades carbonatadas das amostras não vibradas em relação as vibradas, de modo que o fato de não ser realizado o adensamento do concreto, contribui drasticamente para o avanço da frente de carbonatação nas estruturas, reduzindo sua vida útil. Assim percebeu-se que entre as amostras de mesma dimensão houve uma redução de vida útil de mais de 50\% em relação das amostras vibradas para as não vibradas.

O estudo permitiu a percepção que, apesar dos fatores externos proporcionados pelo meio ambiente em que a estrutura está inserida, os fatores relacionados exigências mínimas de projeto e a boa prática da execução, regulamentados pela NBR 6118 (ABNT, 2014) e a NBR 14931 (ABNT, 2004) constribuem para uma melhor durabilidade das estruturas de concreto armado. Fatores estes tratados nas pesquisas de Kulakowski (2002), Wang, Su e Du (2018) e Andrade (2020). 
De modo geral, conclui-se que o cobrimento nominal somado ao adensamento, são pontos de suma importância para o prolongamento da vida útil dos pilares de concreto armado. Assim, ainda que dimensionado de forma correta e seguido o dimensionamento, se os procedimentos de execução não forem adequados, compromete-se a vida útil do sistema.

\section{REFERÊNCIAS}

ANDRADE, C. Evaluation of the degree of carbonation od concretes in three environments. Construction and Building Materials. Vol. 230, p. 116804. Elsevier, 2020.

ASSOCIAÇÃO BRASILEIRA DE NORMAS TÉCNICAS. NBR 6118: Projeto de estruturas de concreto Procedimento. Rio de Janeiro, 2003.

ASSOCIAÇÃO BRASILEIRA DE NORMAS TÉCNICAS. NBR 6118: Projeto de estruturas de concreto Procedimento. Rio de Janeiro, 2014.

ASSOCIAÇÃO BRASILEIRA DE NORMAS TÉCNICAS. NBR 7211: Agregados para concreto - Especificação. Rio de Janeiro, 2009.

ASSOCIAÇÃO BRASILEIRA DE NORMAS TÉCNICAS. NBR 14931: Execução de estruturas de concreto Procedimento. Rio de Janeiro, 2004.

ASSOCIAÇÃO BRASILEIRA DE NORMAS TÉNICAS. NBR 15575: Edificações habitacionais - Desempenho. Rio de Janeiro, 2013.

ASSOCIAÇÃO BRASILEIRA DE NORMAS TÉNICAS. NBR 16697: Cimento Portland - Requisitos. Rio de Janeiro, 2018.

FERREIRA, M.B. Estudo da carbonatação natural de concretos com diferentes adições minerais após 10 anos de exposição. Dissertação (Mestrado em Engenharia civil) - Universidade Federal de Goiás. Goiânia, 2013. Disponível em: < https://repositorio.bc.ufg.br/tede/handle/tede/3448>. Acesso em: 19 set. 2019.

HELENE, P.R.L. A nova NB 1/2003 (NBR 6118) e a vida útil das estruturas de concreto. In: II Seminário de patologia das edificações do LEME/UFRGS. Porto Alegre, 2004. Disponível em: <https://www.phd.eng.br/wpcontent/uploads/2014/06/185.pdf>. Acesso em: 28 set. 2019.

KULAKOWSKI, M.P. Contribuição ao estudo da carbonatação em concretos e argamassas compostos com adição de sílica ativa. Tese (Doutorado) - Universidade Federal do Rio Grande do Sul. Porto Alegre, 2002. Disponível em: <https://www.lume.ufrgs.br/bitstream/handle/10183/3594/000390188.pdf?sequence=1>. Acesso em: 19 set. 2019.

POSSAN, E. Modelagem da carbonatação e previsão de vida útil de estruturas de concreto em ambiente urbano. Tese (Doutorado) - Universidade Federal do Rio Grande do Sul. Porto Alegre, 2010. Disponível em: <https://www.lume.ufrgs.br/bitstream/handle/10183/28923/000773564.pdf?sequence=1\&isAllowed=y>. Acesso em: 20 set. 2019.

POSSAN, E.; DEMOLINER, C. A. Desempenho, durabilidade e vida útil das edificações: Abordagem geral. Revista Técnico-Científica do CREA-PR - ISSN 2358-5420 - 1 ed, out. 2013. Disponível em: <http://creaprw16.creapr.org.br/revista/Sistema/index.php/revista/article/viewFile/14/10>. Acesso em: 08 ago. 2019.

RILEM RECOMMENDATIONS. CPC-18 Measurement of hardened concrete carbonation depth. Materials and Structures. 1988.

SINDICATO NACIONAL DA INDÚSTRIA DO CIMENTO. Produção de cimento em 2016. Disponível em: <http://snic.org.br/numeros-do-setor.php>. Acesso em: 20 out. 2019.

TUUTTI, K. Corrosion of steel in concrete. Swedish Cement and Concrete Reserarch Institute. Stockholm, 1982.

WANG, J.; SU, H.; DU, J. Influence of coupled effects between flexural tensile stress and carbonation time on the carbonation depth of concrete. Construction and Building Materials. Vol. 190, p. 439-451. Elsevier, 2018. 